\title{
Estimation of surface soil organic matter using a ground-based active sensor and aerial imagery
}

\author{
D. F. Roberts • V. I. Adamchuk • J. F. Shanahan • R. B. Ferguson • \\ J. S. Schepers
}

(C) Springer Science+Business Media, LLC 2010

\begin{abstract}
Active canopy sensors are currently being studied as a tool to assess crop $\mathrm{N}$ status and direct in-season $\mathrm{N}$ applications. The objective of this study was to use a variety of strategies to evaluate the capability of an active sensor and a wide-band aerial image to estimate surface soil organic matter (OM). Grid soil samples, active sensor reflectance and bare soil aerial images were obtained from six fields in central Nebraska before the 2007 and 2008 growing seasons. Six different strategies to predict OM were developed and tested by dividing samples randomly into calibration and validation datasets. Strategies included uniform, interpolation, universal, field-specific, intercept-adjusted and multiplelayer prediction models. By adjusting regression intercept values for each field, OM was predicted using a single sensor or image data layer. Across all fields, the uniform and universal prediction models resulted in less accurate predictions of OM than any of the other methods tested. The most accurate predictions of OM were obtained using interpolation, field-specific and intercept-adjusted strategies. Increased accuracy in mapping soil OM using an active sensor or aerial image may be achieved by acquiring the data when there is minimal surface residue or where it has been excluded from the sensor's field-ofview. Alternatively, accuracy could be increased by accounting for soil moisture content with supplementary sensors at the time of data collection, by focusing on the relationship
\end{abstract}

D. F. Roberts $(\bowtie)$

Department of Plant and Soil Sciences, Mississippi State University, 117 Dorman Hall, Mississippi State, MS 39762, USA

e-mail: droberts@pss.msstate.edu

V. I. Adamchuk

Department of Biological Systems Engineering, University of Nebraska-Lincoln, 203 L.W. Chase Hall, Lincoln, NE 68583, USA

J. F. Shanahan · J. S. Schepers

USDA-ARS, Agroecosystem Management Research Unit, 112 USDA National Agroforestry Center, Lincoln, NE 68583, USA

R. B. Ferguson

Department of Agronomy and Horticulture, University of Nebraska-Lincoln, 377 Plant Science, Lincoln, NE 68583, USA 
between soil reflectance and soil OM content in the $0-1 \mathrm{~cm}$ soil depth or through the use of a subsurface active optical sensor.

Keywords Near-infrared (NIR) - Visible (VIS) - Root mean squared error (RMSE) . Mean absolute error (MAE) · Organic matter $(\mathrm{OM})$

\section{Introduction}

In recent years, there has been growing concern about the potential environmental hazards from excessive uniform fertilizer and herbicide application rates to spatially-variable landscapes. Soil with larger organic matter (OM) content requires higher chemical application rates of some herbicides because of adsorption of the herbicide on the cation exchange complex. However, spatial variation of soil contributes to both over- and underapplication of crop inputs within fields. Unused fertilizers and over-applied herbicides are subject to environmental processes and can eventually contaminate surface and groundwater (Diaz 2001; Weber et al. 2006). Precision farming technologies seek to account for spatial variation in soil or crop properties by changing application rates based on field characteristics (Blackmer and White 1998). Because many current herbicide and fertilizer recommendations depend on soil OM content, technologies that account for its spatial variation could potentially reduce the environmental hazards associated with over-applying crop production inputs.

Soil OM is one of many soil properties that influence soil optical reflectance (Krishnan et al. 1980). Large soil OM content is usually associated with high soil fertility and is often observed in the field as a dark surface horizon in the soil profile. Previous studies classified soil color based on Munsell color charts (Alexander 1969; Steinhardt and Franzmeier 1979; Schulze et al. 1993). Schulze et al. (1993) found soil OM content to be predictable using Munsell soil color values $\left(R^{2}>0.90\right)$. This relationship was accurate provided that soil texture did not vary widely within a given landscape. They also found that the relationship between soil color values and OM should be calibrated for different landscapes. Furthermore, they found spectroscopic matching of soil reflectance was more accurate for determining soil color than visual matching alone.

Although the relationship between soil color and OM is useful, practical application of this relationship requires large scale assessment of variability in soil color. In the 1980s and 1990s there was an increase in the classification of soil color by spectral sensors pulled through the surface soil (Griffis 1985; Pitts et al. 1986; Sudduth and Hummel 1993). Previous studies have shown these ground-based sensors can predict soil OM content successfully (Griffis 1985; Pitts et al. 1986; Sudduth and Hummel 1991). However, problems with calibration may occur because soil color and reflectance properties are a function of moisture, texture, chemical composition and parent material, in addition to soil OM (Sudduth and Hummel 1993).

Remote sensing offers a practical means of assessing the spatial variation in fields across broad geographic areas (Scharf et al. 2002). Schepers et al. (2004) used soil brightness from an aerial image as a data layer in conjunction with elevation and soil electrical conductivity to delineate management zones within a field. Gomez et al. (2008) compared the use of satellite imagery with a ground-based spectrometer to determine soil organic carbon. They found that predictions of soil organic carbon using satellite imagery were less accurate than with a spectrometer. Chen et al. (2000) collected soil samples from areas within a field of varying soil brightness levels determined from a color slide and 
predicted soil organic carbon with $98 \%$ accuracy. Chen et al. (2005) predicted soil organic carbon $\left(R^{2} \sim 0.8-0.9\right)$ using either a USDA Farm Service Agency aerial image or a multiband satellite image. They noted, however, that the regression models differed between the three fields in their study. In addition, because of the trend toward conservation tillage systems (Knowler and Bradshaw 2007) bare soil imagery may be increasingly difficult to obtain, making it less feasible to predict surface OM accurately from an image. For this reason, ground-based tools such as active canopy sensors could be useful for estimating surface soil organic matter content across multiple fields.

Active crop canopy reflectance sensors have been studied as a ground-based sensing tool to assess in-season plant nitrogen $(\mathrm{N})$ status and to direct spatially-variable $\mathrm{N}$ applications (Dellinger et al. 2008; Raun et al. 2002; Raun et al. 2005; Roberts et al. 2009; Schmidt et al. 2009; Shanahan et al. 2008; Solari et al. 2008). Active sensors are commercially available tools that generate modulated light in the visible (VIS; 400-700 nm) and near-infrared (NIR; 700-1000 nm) regions of the electromagnetic spectrum. Although active sensors are currently being studied to assess plant $\mathrm{N}$ status during the growing season, they could also provide a possible ground-based method to assess soil color and predict soil OM content. However, little work has been done to confirm this hypothesis. Soil OM predicted by an active sensor could potentially provide an alternative to aerial imagery-based $\mathrm{OM}$ prediction. Use of an active sensor to delineate a soil property such as $\mathrm{OM}$ might also help to refine current active sensor-based in-season $\mathrm{N}$ applications, as suggested by Shanahan et al. (2008). Therefore, the objective of this study was to use a variety of strategies to evaluate the capability of an active sensor and a wide-band aerial image to estimate surface soil OM.

\section{Materials and methods}

\section{Research fields}

This research was conducted on six sprinkler-irrigated production fields in central Nebraska during 2007 (Fields 1, 2 and 3) and 2008 (Fields 4, 5 and 6) (Fig. 1; Table 1). Central Nebraska has a continental climate with average annual precipitation of $60-70 \mathrm{~cm}$. At the time of data acquisition, there was a moderate amount of crop residue still present on the soil surface in all fields (covering $\sim 25 \%$ of the soil surface). Each field has $2-4$ soil

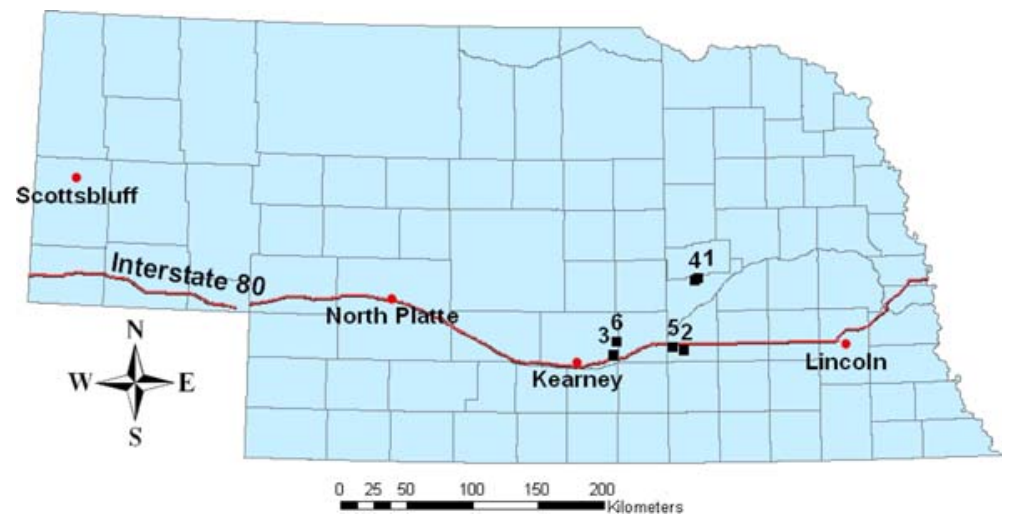

Fig. 1 Map of Nebraska (USA) indicating the locations of the six fields studied 


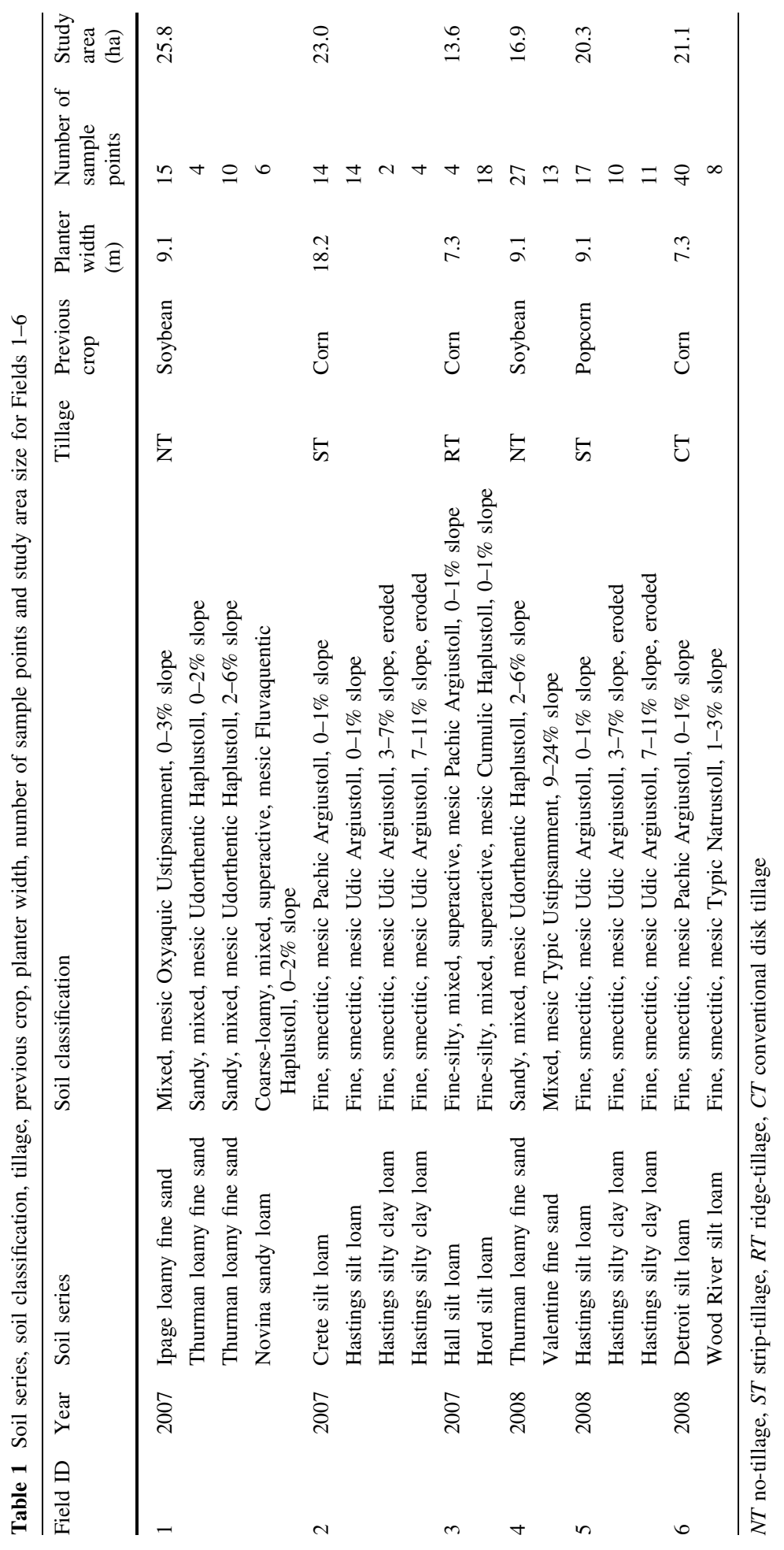


series (Table 1), resulting in within-field variation in soil $\mathrm{OM}$ and soil color values. The elevation in Fields 2, 4 and 5 varies considerably $(\sim 8-10 \mathrm{~m})$, whereas Fields 1, 3 and 6 have little to no relief $(<3 \mathrm{~m})$.

Within-field data collection

Soil samples were taken from grid points within each field before the corn was planted (Table 1). In 2007, samples were taken from a 0.7 ha $(85 \times 85 \mathrm{~m})$ offset grid from Fields 1,2 and 3. With an offset grid, each transect of sampling points is offset a certain distance from the previous transect. This provides more information at a lower cost than a traditional square grid. In 2008, to reduce the amount of unexplained spatial variation in soil properties, samples in Fields 4, 5 and 6 were taken on a 0.4-ha $(63 \times 63 \mathrm{~m})$ offset grid. Soil samples were taken from the topsoil (0-20 cm depth) using hand probe corers. Although soil reflectance is determined from the surface 1-cm soil depth, current soil fertility recommendations by the University of Nebraska are based on OM content at 0-20 cm depth (Shapiro et al. 2003). A total of 6-8 soil cores were taken in a 3-m radius around each sampling point. All cores for a given sampling point were hand-mixed and a representative sub-sample was kept for laboratory analysis. Samples were air-dried and ground to pass through a $2 \mathrm{~mm}$ sieve. Laboratory analysis of soil OM content was done according to the loss-on-ignition (LOI) method, as outlined by Nelson and Sommers (1996), and reported as $\mathrm{g} \mathrm{OM} \mathrm{kg}^{-1}$ of soil.

Active sensor readings were recorded from each field at the time of planting. The active canopy sensor used for this study was the ACS-210 Crop Circle ${ }^{1}$ (Holland Scientific, Inc., Lincoln, NE, USA). This sensor generates modulated light in the VIS and NIR regions of the electromagnetic spectrum and measures canopy reflectance with VIS (590 $\pm 5.5 \mathrm{~nm}$, sensor $\left._{\mathrm{AMBER}}\right)$ and NIR detectors $\left(880 \pm 10 \mathrm{~nm}\right.$, sensor $\left.{ }_{\mathrm{NIR}}\right)$. To acquire sensor readings, the sensor and data logger were mounted on the front of an all-terrain vehicle (ATV) $\sim 0.6 \mathrm{~m}$ above the soil surface. The sensor was positioned over the soil surface in the nadir view, producing a footprint of approximately $8 \times 40 \mathrm{~cm}$; the long dimension of this footprint was oriented parallel to the direction of travel. The sensor footprint was positioned over the row of planted corn to minimize the amount of crop residue in the sensor's field-of-view as the ATV followed behind the planter. Because soil reflectance can be greatly influenced by surface soil moisture content (Idso et al. 1975; Post et al. 2000), a distance of $\sim 90 \mathrm{~m}$ was maintained between the ATV and the planter. This separation distance minimized the effects of dust during data collection and inconvenience to the farmer during planting. This also resulted in the data being recorded $<1 \mathrm{~min}$ after the soil had been disturbed, providing a moderate amount of soil water content and soil color differentiation. The distance between consecutive ATV passes across the field was equal to the planter width (Table 1). A Garmin 18 (Garmin International, Inc., Olathe, KS, USA) Global Positioning System (GPS) receiver with an update rate of $5 \mathrm{~Hz}$ was mounted next to the sensor. Sensor readings were recorded at $10 \mathrm{~Hz}$ while the ATV traveled $\sim 10 \mathrm{~km} \mathrm{~h}^{-1}$, resulting in readings $\sim 0.56 \mathrm{~m}$ apart. Linear interpolation was applied to assign unique geographic coordinates to each recorded measurement. To align sensor readings with exact grid sample locations, sensor readings were further interpolated using inverse-distance weighting (IDW) and exported with a 2-m pixel resolution. Sensor ${ }_{\mathrm{AMBER}}$ and sensor $_{\mathrm{NIR}}$

\footnotetext{
${ }^{1}$ Mention of a trade name, proprietary product, or company name is for presentation clarity and does not imply endorsement by the authors, University of Nebraska-Lincoln, USDA-ARS, or exclusion of other products that may also be suitable.
} 
readings for each grid sample location were extracted using zonal statistics in ArcMap 9.2 (ESRI, Redlands, CA, USA).

Image acquisition and analysis

Bare soil images for each field were obtained by Cornerstone Mapping, Inc. (Lincoln, NE, USA) on May 25, 2007 (Fields 1, 2 and 3) and May 20, 2008 (Fields 4, 5 and 6) when the sky was clear. The most recent rainfall events prior to each image acquisition were not
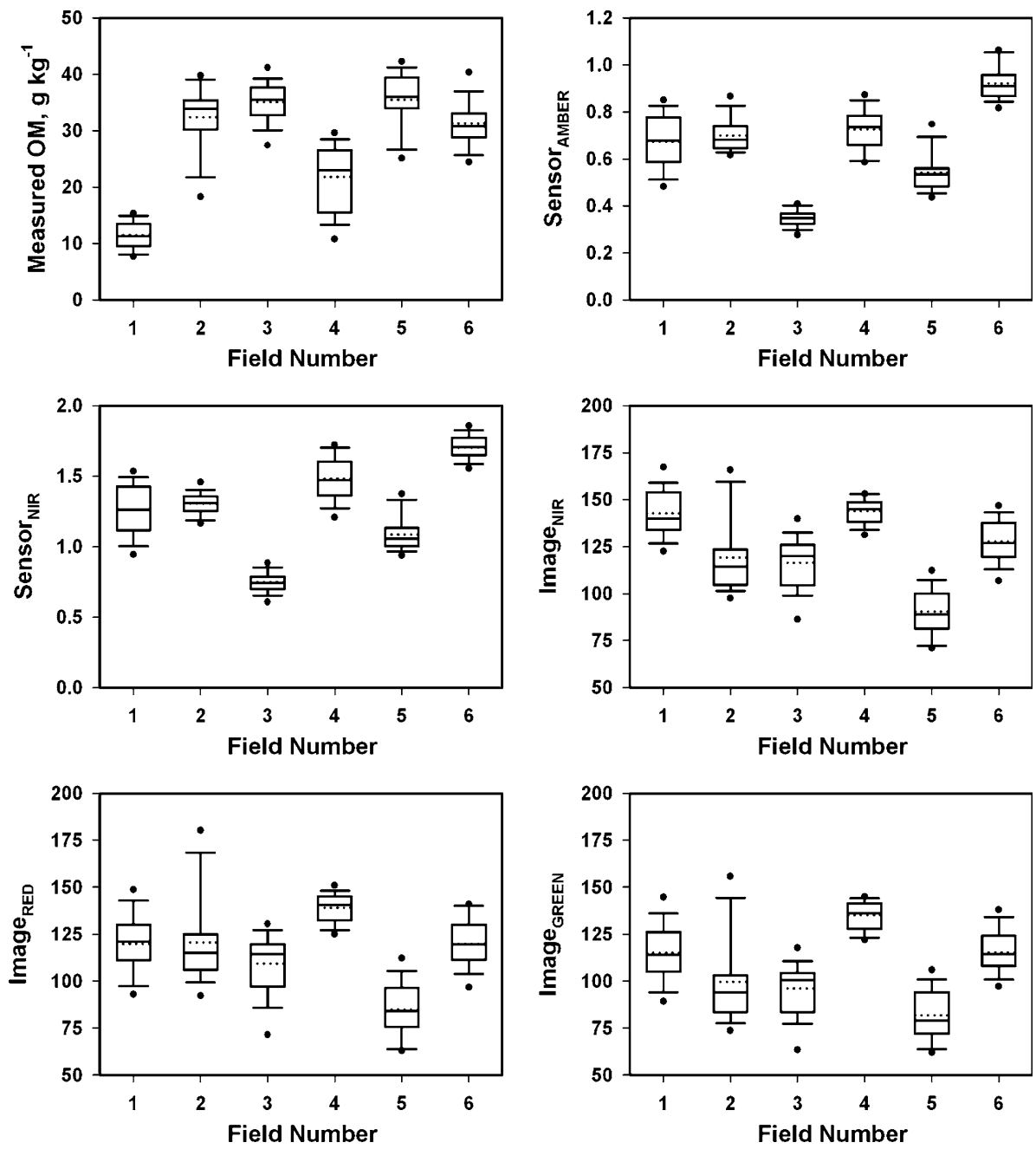

Fig. 2 Box-and-whisker diagrams of measured OM, sensor ${ }_{\mathrm{AMBER}}$, sensor ${ }_{\mathrm{NIR}}$, image , $_{\mathrm{NIR}}$, image $\mathrm{i}_{\mathrm{RED}}$ and image $_{\text {GREEN }}$ for Fields 1-6. The lower and upper limits of each box are the 25 th and 75 th percentiles, the lower and upper whiskers represent the 10th and 90th percentiles, the large dots represent the 5th and 95th percentiles, the horizontal line in the center of each box represents the median and the dotted line represents the mean values for each dependent variable. Sensor ${ }_{\mathrm{AMBER}}$ and sensor ${ }_{\mathrm{NIR}}$ are reported in unitless sensor pseudo-reflectance values. Image $\mathrm{NIR}_{\mathrm{N}}$, image $_{\mathrm{RED}}$ and image $_{\mathrm{GREEN}}$ are reported in image digital brightness values (0-255) 
Table 2 Correlation $(p<0.1)$ of soil organic matter $(O M)$, two sensor bands (sensor ${ }_{\mathrm{AMBER}}$ and sensor $\left._{\mathrm{NIR}}\right)$, and three image bands (image GREEN image $_{\text {RED }}$ and image $_{\mathrm{NIR}}$ ) for Fields 1-6

\begin{tabular}{|c|c|c|c|c|c|c|}
\hline Field & $\mathrm{OM}$ & Sensor $_{\mathrm{AMBER}}$ & Sensor $_{\text {NIR }}$ & Image $_{\text {GREEN }}$ & Image $_{\text {RED }}$ & Image $_{\text {NIR }}$ \\
\hline \multicolumn{7}{|l|}{1} \\
\hline OM & 1 & & & & & \\
\hline Sensor $_{\text {AMBER }}$ & -0.73 & 1 & & & & \\
\hline Sensor $_{\text {NIR }}$ & -0.72 & 0.99 & 1 & & & \\
\hline Image $_{\text {GREEN }}$ & -0.66 & 0.63 & 0.63 & 1 & & \\
\hline Image $_{\text {RED }}$ & -0.70 & 0.69 & 0.69 & 0.99 & 1 & \\
\hline Image $_{N I R}$ & -0.67 & 0.61 & 0.62 & 0.98 & 0.97 & 1 \\
\hline \multicolumn{7}{|l|}{2} \\
\hline $\mathrm{OM}$ & 1 & & & & & \\
\hline Sensor $_{A M B E R}$ & -0.88 & 1 & & & & \\
\hline Sensor $_{\text {NIR }}$ & -0.77 & 0.80 & 1 & & & \\
\hline Image $_{\text {GREEN }}$ & -0.74 & 0.73 & 0.66 & 1 & & \\
\hline Image $_{\text {RED }}$ & -0.77 & 0.76 & 0.67 & 0.99 & 1 & \\
\hline Image $_{\text {NIR }}$ & -0.71 & 0.69 & 0.67 & 0.99 & 0.98 & 1 \\
\hline \multicolumn{7}{|l|}{3} \\
\hline $\mathrm{OM}$ & 1 & & & & & \\
\hline Sensor $_{\text {AMBER }}$ & -0.38 & 1 & & & & \\
\hline Sensor $_{\text {NIR }}$ & -0.40 & 0.99 & 1 & & & \\
\hline Image $_{\text {GREEN }}$ & -0.77 & 0.40 & 0.44 & 1 & & \\
\hline Image $_{\text {RED }}$ & -0.73 & 0.43 & 0.47 & 0.99 & 1 & \\
\hline Image $_{\mathrm{NIR}}$ & -0.77 & NS & 0.38 & 0.99 & 0.98 & 1 \\
\hline \multicolumn{7}{|l|}{4} \\
\hline $\mathrm{OM}$ & 1 & & & & & \\
\hline Sensor $_{\text {AMBER }}$ & NS & 1 & & & & \\
\hline Sensor $_{\text {NIR }}$ & NS & 0.98 & 1 & & & \\
\hline Image $_{\text {GREEN }}$ & -0.46 & NS & NS & 1 & & \\
\hline Image $_{\text {RED }}$ & -0.38 & NS & NS & 0.96 & 1 & \\
\hline Image $_{\text {NIR }}$ & -0.38 & NS & NS & 0.96 & 0.99 & 1 \\
\hline \multicolumn{7}{|l|}{5} \\
\hline $\mathrm{OM}$ & 1 & & & & & \\
\hline Sensor $_{\mathrm{AMBER}}$ & -0.81 & 1 & & & & \\
\hline Sensor $_{\mathrm{NIR}}$ & -0.81 & 0.98 & 1 & & & \\
\hline Image $_{\text {GREEN }}$ & -0.59 & 0.56 & 0.55 & 1 & & \\
\hline Image $_{\text {RED }}$ & -0.57 & 0.52 & 0.52 & 0.99 & 1 & \\
\hline Image $_{N I R}$ & -0.52 & 0.46 & 0.47 & 0.97 & 0.99 & 1 \\
\hline \multicolumn{7}{|l|}{6} \\
\hline $\mathrm{OM}$ & 1 & & & & & \\
\hline Sensor $_{\text {AMBER }}$ & -0.48 & 1 & & & & \\
\hline Sensor $_{\mathrm{NIR}}$ & -0.40 & 0.92 & 1 & & & \\
\hline Image $_{\text {GREEN }}$ & NS & NS & NS & 1 & & \\
\hline Image $_{\text {RED }}$ & NS & NS & NS & 0.98 & 1 & \\
\hline Image $_{N I R}$ & NS & NS & NS & 0.96 & 0.99 & 1 \\
\hline
\end{tabular}


Table 2 continued

\begin{tabular}{lccllll}
\hline Field & OM & Sensor $_{\text {AMBER }}$ & Sensor $_{\text {NIR }}$ & Image $_{\text {GREEN }}$ & Image $_{\text {RED }}$ & Image $_{\text {NIR }}$ \\
\hline Overall & & & & & & \\
$\quad$ OM & 1 & & & & & \\
Sensor & & & & & \\
Sensor $_{\text {NIR }}$ & -0.25 & 0.98 & 1 & 1 & 1 & 1 \\
Image $_{\text {GREEN }}$ & -0.59 & 0.51 & 0.55 & 0.95 & 0.94 & 1 \\
Image $_{\text {RED }}$ & -0.52 & 0.46 & 0.47 & 0.44 & 0.94 & \\
Image $_{\text {NIR }}$ & -0.70 & 0.43 & & & & \\
\hline
\end{tabular}
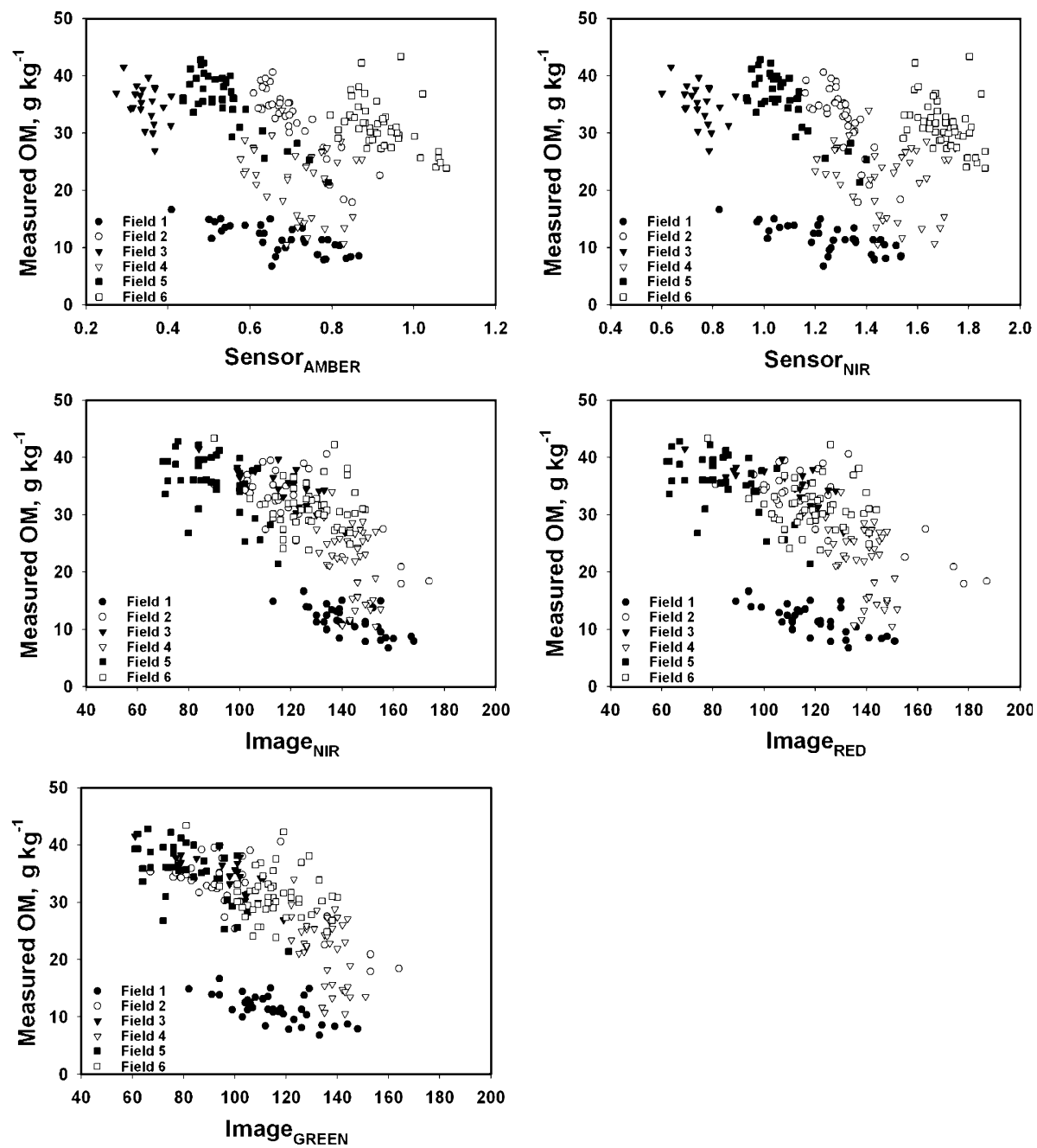

Fig. 3 All data points of measured $\mathrm{OM}$ versus sensor ${ }_{\mathrm{AMBER}}$, sensor ${ }_{\mathrm{NIR}}$, image $\mathrm{NIR}_{\mathrm{N}}$, image RED $_{\text {and }}$ image $_{\text {GREEN }}$ for Fields 1-6 
recorded. A digital sensor system (Applanix Corporation, Richmond Hill, Ontario, Canada) mounted on an aircraft was used to acquire the images. This sensor had a charge-coupled device (CCD) array of $4092 \times 4077$ pixels, 8-bit radiometric resolution (0-255 brightness values) and broad spectral channels in the green $(510-600 \mathrm{~nm}$; image GREEN $)$, red (600$720 \mathrm{~nm}$; image $\left._{\text {RED }}\right)$ and NIR $\left(720-920 \mathrm{~nm}\right.$; image $\left.\mathrm{NIR}_{\mathrm{N}}\right)$ portions of the electromagnetic spectrum. In the CCD array, each pixel was converted into an electrical charge, with the intensity being related to a particular color in the light spectrum (0-255). Thus, each pixel consisted of three digital brightness numbers, representing the values for image ${ }_{\text {GREEN }}$,

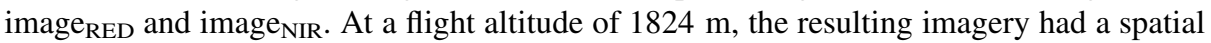
resolution of $0.3 \mathrm{~m}$.

Images were georectified by Cornerstone Mapping, Inc. using POSPAC processing software (Applanix Corporation, Richmond Hill, Ontario, Canada). Further georectification was done using the AutoSync tool in ERDAS Imagine 9.1 (ERDAS Inc., Norcross, GA, USA) and rectifying the image to a base image obtained during the growing season. The base image was georectified with POSPAC processing software and further positioning was done using eight ground control points obtained with a sub-meter accuracy Trimble GeoXT GPS handheld unit (Trimble Navigation Limited, Sunnyvale, CA, USA). To account for slight deviations in GPS positions between soil sampling locations and image pixels, bilinear resampling was done in ArcGIS 9.2 to a 2-m spatial resolution. A low-pass $5 \times 5$ filter was applied to each image in ERDAS Imagine 9.1 to reduce the variance among pixels. Digital brightness values for each soil sampling location were extracted as data.
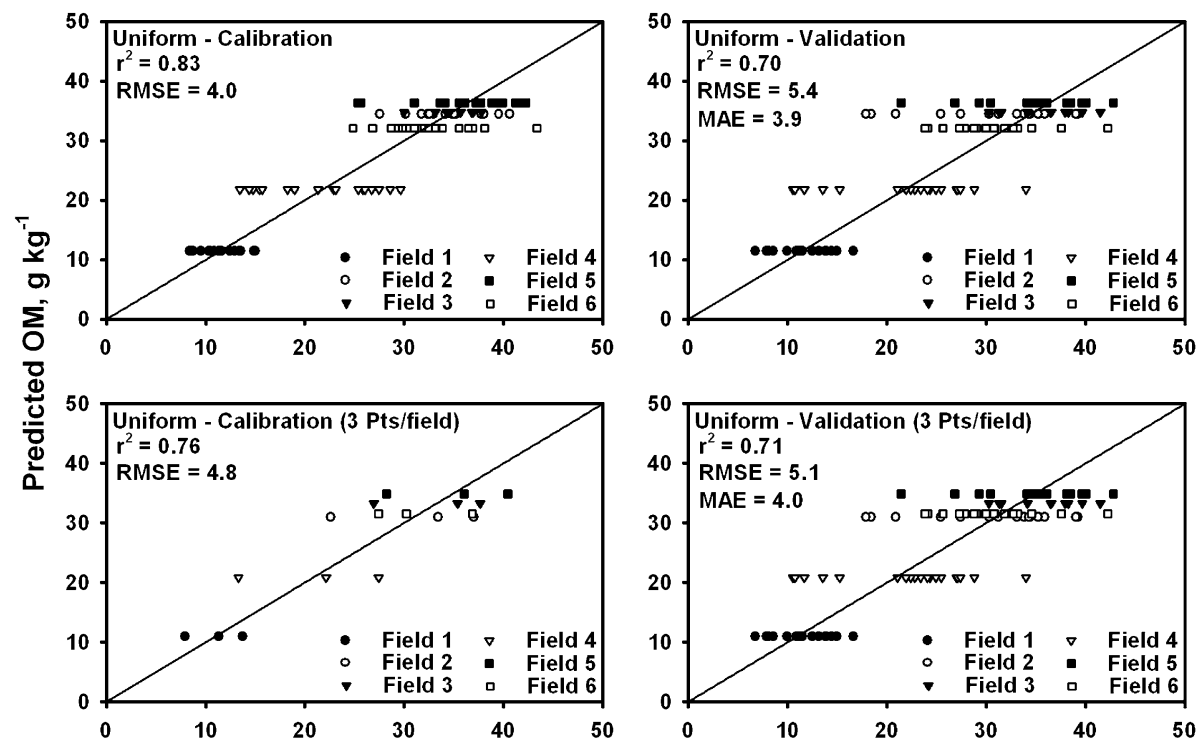

Measured OM, $\mathrm{g} \mathrm{kg}^{-1}$

Fig. 4 Relationship of predicted versus measured OM for Fields 1-6 using the uniform OM prediction strategy for each field. Average OM values were determined using all data points from each field, or by calculating the average of three data points selected from high, medium and low OM areas of each field. The RMSE and MAE are in the same units as measured and predicted OM 
Model development and validation

Prior to data analysis, data points from each field were divided into three datasets. For dataset 1, sample points for individual fields were arranged in order of increasing OM levels. An equal number of sample points was assigned to high, medium and low OM intervals for each field. One sample point from each interval was removed randomly for use in model development (discussed later). The remaining data points in each field were re-randomized and divided equally into calibration and validation datasets. Different strategies to predict OM using grid sampling as well as aerial imagery and ground-based sensing were investigated. These strategies were selected to compare OM prediction techniques commonly used by researchers and other approaches derived after initial data inspection. Strategies included uniform, interpolation, universal, field-specific, interceptadjusted and multiple-layer prediction models.

The uniform prediction model is a commonly used method in production agriculture; it assumes that an average OM value is applied to the entire field (average of all sample locations in the calibration dataset). Because soil sample data on a grid may not be available for every field, we tested an alternative prediction model using three data points representing areas of high, medium and low levels of OM for each field. For the interpolation prediction model, inverse distance squared (IDW) in the Geostatistical Analyst of ArcGIS 9.2 was used to interpolate OM from the calibration dataset for each field.

For the universal prediction model, a simple linear regression model with $\mathrm{OM}$ as the dependent variable was applied across all fields according to the following equation:

$$
\mathrm{OM}_{\text {universal }}=\text { intercept }_{\text {universal }}+\text { slope }_{\text {universal }} \cdot X \text {, }
$$

where $X$ was the sensor output or aerial imagery value for a specific spectral band. Similarly, the field-specific model is given by:

$$
\mathrm{OM}_{\text {field-specific }}=\text { intercept }_{\text {field-specific }}+\text { slope }_{\text {field-specific }} \cdot X,
$$

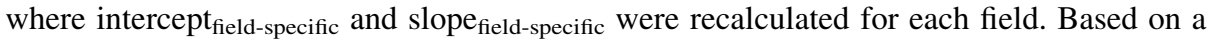
preliminary inspection of the data, a regression model that adjusted only the intercept for each field appeared to be more practical because only a few calibration samples would be required for prediction in each field. This intercept-adjusted OM prediction model using one slope and field-specific intercepts was calculated as:

$$
\mathrm{OM}_{\text {intercept-adjusted }}=\text { intercept }_{\text {field-specific }}+\text { slope }_{\text {universal }} \cdot X,
$$

where intercept $t_{\text {field-specific }}$ was the adjusted intercept for individual fields, and slope universal $_{\text {a }}$ was one regression slope applied across all fields. In this equation, intercept field-specific $_{\text {was }}$ calculated from the average of the three data points (high, medium and low levels of OM) removed from each field before model development. This was done by calculating one

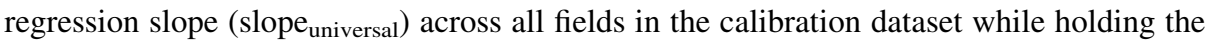
intercept constant at zero, followed by calculating the average intercept value for each field

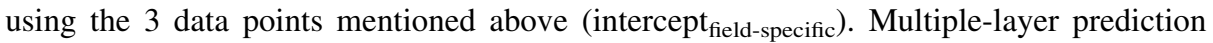
models were derived using a combination of the best performing sensor and imagery data from the intercept-adjusted model.

The OM values predicted using all the listed models were compared with actual measurements using both calibration and validation datasets. Regression models were developed using calibration datasets; the resulting models were then applied to the validation datasets. Comparison of predicted and measured OM values in calibration datasets 
were used to illustrate the strength of the models developed, but did not have practical application. On the other hand, the analysis performed using the validation dataset provided an objective comparison among all the models for each field as well as for the entire dataset.

Each prediction model was evaluated using root mean squared error (RMSE) and the coefficient of determination $\left(R^{2}\right)$ for a simple linear regression between measured and predicted soil OM. To test for statistical differences between the prediction strategies, the mean absolute error (MAE) was also calculated for each validation dataset. Field-specific and overall MAE estimates were compared using a completely randomized block design $(\alpha=0.05)$. Statistical analyses for this study were done in Microsoft Excel (Microsoft Corp., Redmond, WA, USA) and SAS 9.1 (SAS Institute Inc., Cary, NC, USA).

\section{Results and discussion}

Initial data analysis

Measured OM ranged widely both within and among fields (Fig. 2); average values ranged from 11 to $43 \mathrm{~g} \mathrm{~kg}^{-1}$ across all fields. Within-field OM variation was greatest in Fields 2,4 and 5 (range $=22 \mathrm{~g} \mathrm{~kg}^{-1}$ ), and least in Field 1 (range $=10 \mathrm{~g} \mathrm{~kg}^{-1}$ ). Average measured $\mathrm{OM}$ where the soil is sandy (Fields 1 and $4 ; 17 \mathrm{~g} \mathrm{~kg}^{-1}$ ) was half that of fine-textured soils (Fields 2, 3, 5 and 6; $34 \mathrm{~g} \mathrm{~kg}^{-1}$ ).

Across all fields, sensor ${ }_{\mathrm{AMBER}}$ and sensor $_{\mathrm{NIR}}$ measurements are strongly correlated $\left(r=0.98\right.$; Table 2). Measurements from image ${ }_{\mathrm{GREEN}}$, image $_{\mathrm{RED}}$ and image $\mathrm{e}_{\mathrm{NIR}}$ are also strongly correlated $(r \geq 0.94)$. Relationships between sensor $_{\mathrm{AMBER}}$ or sensor $_{\mathrm{NIR}}$ measurements and image GREEN , image RED $_{\text {, or image }}$ NIR measurements show only moderate correlation $(r=0.4-0.6)$. Sensor AMBER $_{\text {and }}$ sensor ${ }_{\mathrm{NIR}}$ have the strongest correlation to $\mathrm{OM}$ in Fields 2 and 5, the two fields with silt loam soil and substantial relief. For sensor $_{\text {AMBER }}$ and sensor ${ }_{\text {NIR }}$ the correlations to OM are not significant in Field 4. This could potentially be related to the substantial relief in this field and moisture loss from the sandy soil between the time of soil disturbance and data collection. This same reason may also have contributed to weaker correlations between image GREEN $_{\text {, image }}$ RED $_{\text {and }}$ image $_{\text {NIR }}$ to $\mathrm{OM}$ in Field 4. It is not clear why the imagery bands are not significantly correlated to OM in Field 6 (Table 2). For the entire dataset, measured OM is only weakly correlated to both sensor $_{\mathrm{AMBER}}$ and sensor $\mathrm{NIR}(r<-0.3)$, possibly as a result of slight variation in the distance between the ATV and planter during data collection and rapid drying of the soil that may have occurred after soil disturbance. Correlation of OM to imagery bands is moderate $(r=-0.5$ to -0.7$)$. These results provide a broad range in OM, sensor and imagery measurements with which to build prediction models of OM.

Relationships between OM measurements and sensor ${ }_{\mathrm{AMBER}}$, sensor ${ }_{\mathrm{NIR}}$, image $_{\mathrm{GREEN}}$,

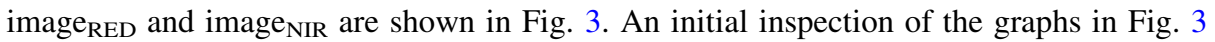
indicates that OM prediction models for Field 1 and possibly Field 4 (sandy soil) would require different intercepts and or slopes than the remaining fields in the analysis (finetextured soil). As shown in Fig. 3, the relationships between measured OM and sensor measurements for fine-textured soil types indicate that field-specific or intercept-adjusted models would need to be developed for accurate prediction of OM by sensors. In contrast, inspection of measured $\mathrm{OM}$ and imagery bands in Fig. 3 indicates that one linear regression model could potentially be applied across the four fields with fine-textured soil. Intercept adjustment of the imagery-based model could possibly provide increased 
Table 3 Summary of accuracy of OM prediction strategy models using both calibration and validation data

\begin{tabular}{|c|c|c|c|c|c|c|}
\hline \multirow[t]{2}{*}{ Strategy } & \multirow[t]{2}{*}{ Data used } & \multicolumn{2}{|c|}{ Calibration } & \multicolumn{3}{|c|}{ Validation } \\
\hline & & $R^{2}$ & $\begin{array}{l}\text { RMSE } \\
\mathrm{g} \mathrm{kg}^{-1}\end{array}$ & $R^{2}$ & $\begin{array}{l}\text { RMSE } \\
\mathrm{g} \mathrm{kg}^{-1}\end{array}$ & $\begin{array}{l}\text { MAE } \\
\mathrm{g} \mathrm{kg}^{-1}\end{array}$ \\
\hline \multirow[t]{2}{*}{ Uniform } & All points & 0.83 & 4.0 & 0.70 & 5.4 & 3.9 \\
\hline & 3 Points/field & 0.76 & 4.8 & 0.71 & 5.1 & 4.0 \\
\hline Interpolation & IDW & 1.00 & 0.0 & 0.75 & 4.9 & 3.6 \\
\hline \multirow[t]{5}{*}{ Universal } & Sensor $_{\text {AMBER }}$ & 0.05 & 9.5 & 0.08 & 9.2 & 7.4 \\
\hline & Sensor $_{\text {NIR }}$ & 0.04 & 9.5 & 0.07 & 9.2 & 7.4 \\
\hline & Image $_{\mathrm{NIR}}$ & 0.47 & 7.1 & 0.47 & 7.0 & 5.5 \\
\hline & Image $_{\text {RED }}$ & 0.26 & 8.4 & 0.25 & 8.3 & 6.3 \\
\hline & Image $_{\text {GREEN }}$ & 0.33 & 8.0 & 0.32 & 7.9 & 5.8 \\
\hline \multirow[t]{5}{*}{ Field-specific } & Sensor $_{\text {AMBER }}$ & 0.88 & 3.4 & 0.82 & 4.1 & 3.1 \\
\hline & Sensor $_{\mathrm{NIR}}$ & 0.88 & 3.4 & 0.80 & 4.4 & 3.2 \\
\hline & Image $_{N I R}$ & 0.87 & 3.5 & 0.75 & 4.9 & 3.6 \\
\hline & Image $_{\text {RED }}$ & 0.88 & 3.4 & 0.76 & 4.8 & 3.6 \\
\hline & Image $_{\text {GREEN }}$ & 0.88 & 3.4 & 0.76 & 4.8 & 3.5 \\
\hline \multirow[t]{5}{*}{ Intercept-adjusted } & Sensor $_{A M B E R}$ & 0.85 & 3.8 & 0.78 & 4.5 & 3.4 \\
\hline & Sensor $_{\text {NIR }}$ & 0.84 & 4.0 & 0.76 & 4.6 & 3.6 \\
\hline & Image $_{\mathrm{NIR}}$ & 0.85 & 3.9 & 0.78 & 4.5 & 3.4 \\
\hline & Image $_{\text {RED }}$ & 0.86 & 3.8 & 0.79 & 4.4 & 3.3 \\
\hline & Image $_{\text {GREEN }}$ & 0.86 & 3.8 & 0.79 & 4.4 & 3.3 \\
\hline \multirow[t]{5}{*}{ Multiple layers } & Sensor $_{\mathrm{AMBER}}+$ Sensor $_{\mathrm{NIR}}$ & 0.85 & 3.8 & 0.78 & 4.5 & 3.4 \\
\hline & Sensor $_{\mathrm{AMBER}}+\left(\right.$ Image $_{\mathrm{RED}}+$ Image $\left._{\mathrm{GREEN}}\right)$ & 0.87 & 3.6 & 0.82 & 4.1 & 3.1 \\
\hline & Sensor $_{\text {NIR }}+$ Image $_{\text {NIR }}$ & 0.86 & 3.8 & 0.81 & 4.2 & 3.2 \\
\hline & Image $_{\mathrm{NIR}}+\left(\right.$ Image $_{\mathrm{RED}}+$ Image $\left._{\mathrm{GREEN}}\right)$ & 0.86 & 3.7 & 0.80 & 4.3 & 3.4 \\
\hline & Sensor $_{\mathrm{AMBER}}+$ Image $_{\text {GREEN }}$ & 0.87 & 3.6 & 0.82 & 4.1 & 3.1 \\
\hline
\end{tabular}
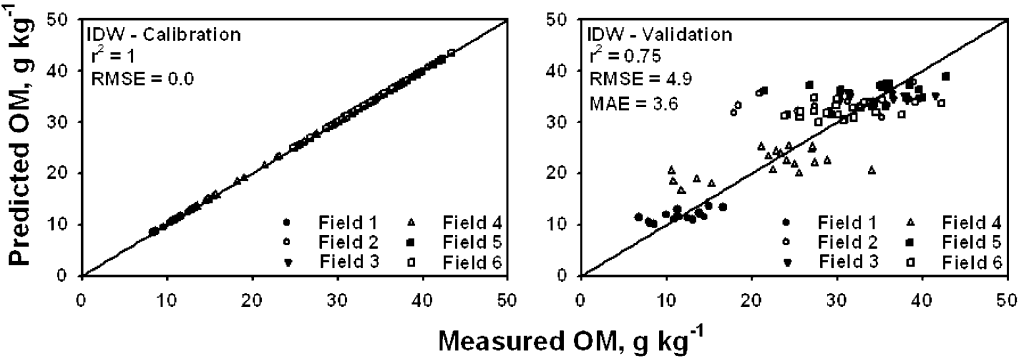

Fig. 5 Calibration and validation results of predicted versus measured OM for Fields 1-6 using inverse distance squared interpolation (IDW). The RMSE and MAE are in the same units as measured and predicted $\mathrm{OM}$

accuracy in the prediction of OM for the fields with sandy soil. The difference in the scatter of points between the sensor and image bands in Fig. 3 is because the digital brightness values for each image were stretched to a range of 0-255. This step in image processing created a site-specific adjustment for each field, resulting in all fine-textured soil types 

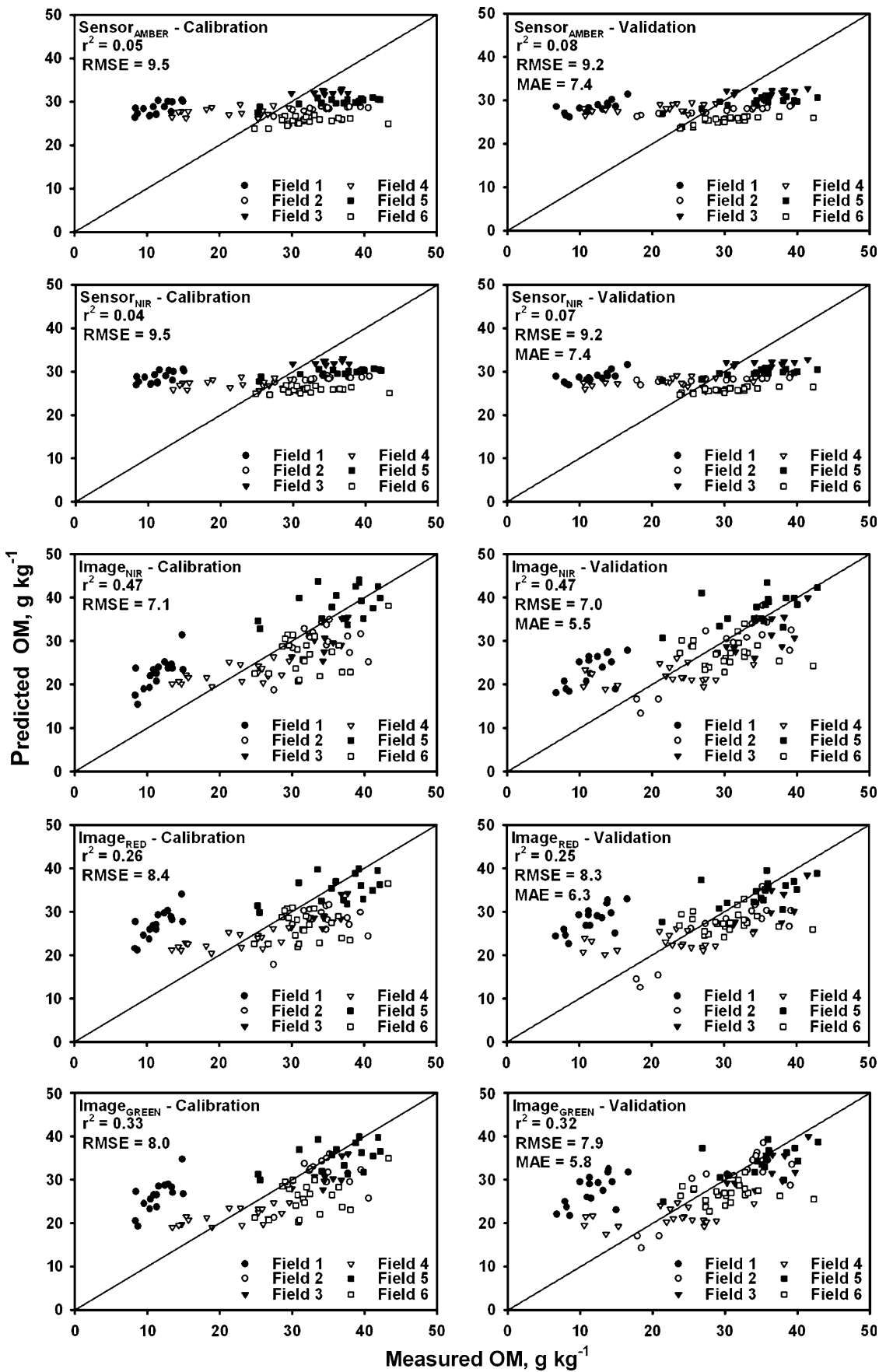

Fig. 6 Calibration and validation results of predicted versus measured OM for Fields 1-6 using a universal regression model developed from and applied across all fields. Single prediction variables include sensor $_{\mathrm{AMBER}}$, sensor $\mathrm{NIR}$, image $_{\mathrm{NIR}}$, image $_{\mathrm{RED}}$ and image $\mathrm{GREEN}$. The RMSE and MAE are in the same units as measured and predicted $\mathrm{OM}$ 
being grouped along a similar slope and intercept. Sensor data were not stretched to a standardized range so that data points for each field have a similar slope, but different intercept values (Fig. 3). In addition, the different slope values for the sandy soil compared to fine-textured soil could possibly be related to soil parent material and soil moisture content at the time of data collection.

\section{Model development and validation}

Results for the uniform OM prediction models are shown in Fig. 4 and Table 3. Use of all calibration points produces a RMSE of $4.0 \mathrm{~g} \mathrm{~kg}^{-1}$, which increases by $1.4 \mathrm{~g} \mathrm{~kg}^{-1}$ when applied to the validation dataset. An RMSE of $4.8 \mathrm{~g} \mathrm{~kg}^{-1}$ results when the average of three selected data points are used instead of the calibration dataset. When this uniform regression model is applied to the validation data, the RMSE increases by $0.3 \mathrm{~g} \mathrm{~kg}^{-1}$, and the resulting RMSE is comparable to the uniform prediction model that used the entire calibration dataset. These results suggest that prediction of $\mathrm{OM}$ from a reduced number of sample points or from a few representative data points from directed sampling could provide error estimates similar to models that use all the data for a field.

The results of IDW interpolation are shown in Fig. 5. For the calibration IDW dataset, the $R^{2}$ values are 1 because IDW is an exact interpolator, and all of the calibration points are used to create the IDW surface. When applied to the validation dataset, IDW produces a RMSE of $4.9 \mathrm{~g} \mathrm{~kg}^{-1}$ and MAE of $3.6 \mathrm{~g} \mathrm{~kg}^{-1}$. This interpolation method predicts OM content more accurately than the uniform prediction models.

Applying a universal simple linear regression model across all fields leads to over-prediction of OM for Fields 1 and 4 (sandy soil) and under-prediction for Fields 2, 3, 5 and 6 (fine-textured soil) (Fig. 6). Universal sensor-based prediction results in substantially weaker model performance $\left(R^{2} \leq 0.08\right.$, RMSE $=9.2 \mathrm{~g} \mathrm{~kg}^{-1}$, MAE $\left.=7.4 \mathrm{~g} \mathrm{~kg}^{-1}\right)$ compared with uniform $\left(R^{2}=0.71\right.$, RMSE $\left.=5.1 \mathrm{~g} \mathrm{~kg}^{-1}, \mathrm{MAE}=4.0 \mathrm{~g} \mathrm{~kg}^{-1}\right)$ or interpolation $\left(R^{2}=0.75, \mathrm{RMSE}=4.9 \mathrm{~g} \mathrm{~kg}^{-1}, \mathrm{MAE}=3.6 \mathrm{~g} \mathrm{~kg}^{-1}\right)$ prediction models (Table 3). Universal imagery-based prediction performs substantially better than the sensor-based models, with image $_{\mathrm{NIR}}$ performing better $\left(R^{2}=0.47, \mathrm{RMSE}=7.0 \mathrm{~g} \mathrm{~kg}^{-1}, \mathrm{MAE}=5.5 \mathrm{~g} \mathrm{~kg}^{-1}\right)$ than image RED $\left(R^{2}=0.25\right.$, RMSE $\left.=8.3 \mathrm{~g} \mathrm{~kg}^{-1}, \mathrm{MAE}=6.3 \mathrm{~g} \mathrm{~kg}^{-1}\right)$ and image GREEN $\left(R^{2}=0.32\right.$, RMSE $\left.=7.9 \mathrm{~g} \mathrm{~kg}^{-1}, \mathrm{MAE}=5.8 \mathrm{~g} \mathrm{~kg}^{-1}\right)$ (Table 3). However, the image $\mathrm{NIR}$ universal prediction model substantially overestimates OM for Field 1 (Fig. 6). These results indicate that a simple linear sensor-based or imagery-based prediction model using one prediction variable will not predict $\mathrm{OM}$ as accurately for these data as the uniform or interpolation prediction strategies. These results agree with findings by others (Schulze et al. 1993), where the model accuracy decreased substantially when samples from a large geographical area with different parent materials were included in a single regression model (universal strategy).

Field-specific models provide the most accurate OM prediction (Fig. 7). When applied to the calibration data, a single sensor or imagery band used to predict OM content results in $R^{2} \geq 0.87$ and RMSE $\leq 3.5 \mathrm{~g} \mathrm{~kg}^{-1}$. When applied to the validation data, either sensor layer ( sensor $_{\mathrm{AMBER}}$ or sensor ${ }_{\mathrm{NIR}}$ ) provides a better prediction of OM than any of the individual imagery bands (Fig. 7; Table 3). For either sensor platform (i.e. sensor or image), visible bands slightly reduce error values compared to their respective NIR bands, indicating that for these data VIS predicts soil OM content more accurately than the NIR bands. The field-specific sensor and imagery calibration provides the most accurate prediction of OM; however, its implementation on a large scale would be impractical due to time and cost for site-specific calibration. Therefore, additional analyses were done to 

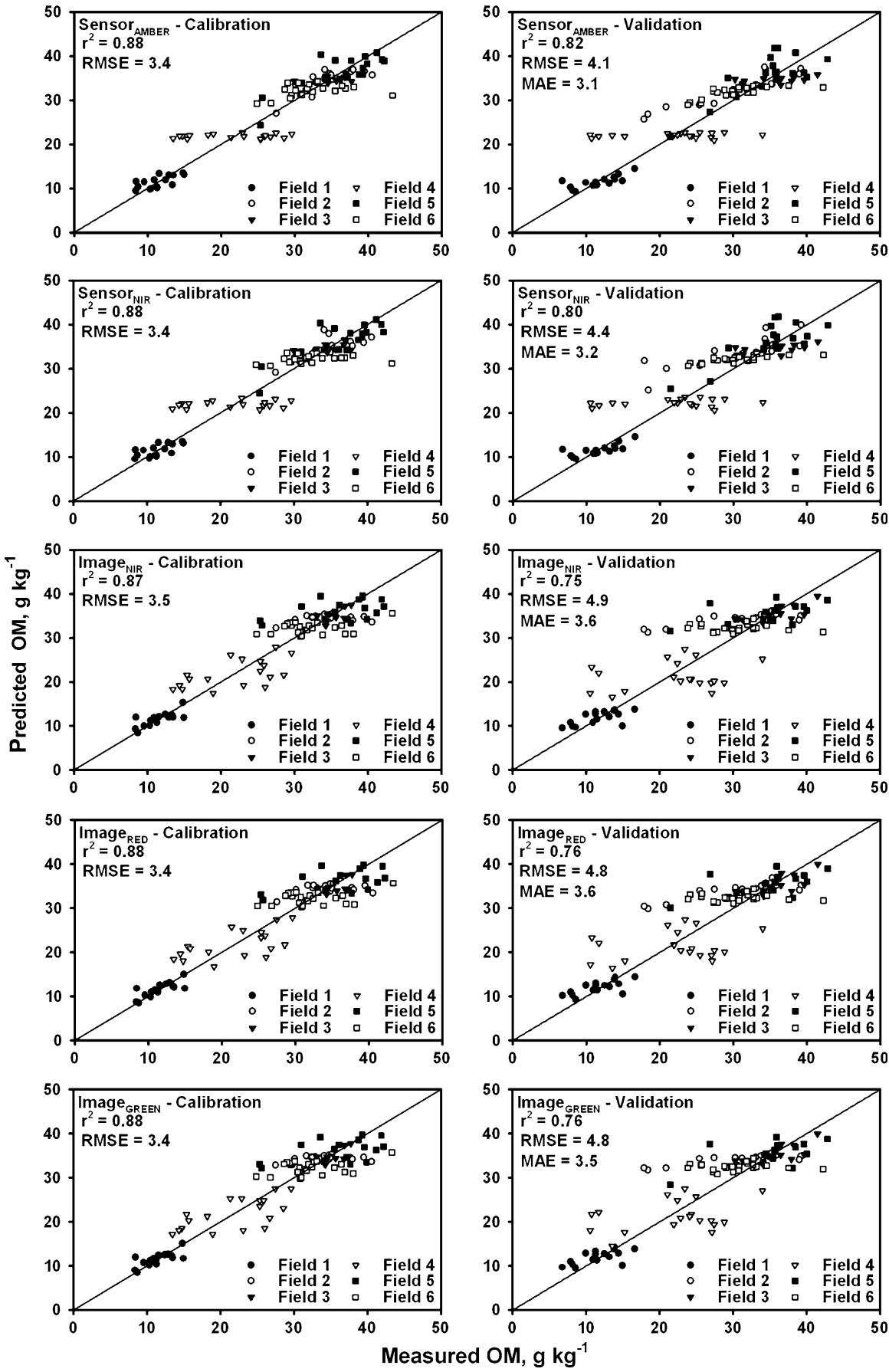

Fig. 7 Calibration and validation results of predicted versus measured OM for Fields 1-6 using a fieldspecific OM prediction strategy. Field regression models were developed from and applied to individual fields. Single prediction variables include sensor ${ }_{\mathrm{AMBER}}$, sensor ${ }_{\mathrm{NIR}}$, image NIR $_{\mathrm{N}}$ image $_{\mathrm{RED}}$ and image GREEN $_{\text {. }}$ The RMSE and MAE are in the same units as measured and predicted OM 
derive a feasible alternative that could potentially be implemented at the farm level with limited time and cost requirements for calibration.

Based on the scatter of the data in the plots in Fig. 3, we tested an intercept-adjusted OM prediction model as a possible alternative to the field-specific strategy. For the calibration data, the intercept-adjusted method results in less accurate predictions of OM for the sensor $\left(R^{2} \geq 0.84, \mathrm{RMSE} \leq 4.0 \mathrm{~g} \mathrm{~kg}^{-1}\right)$ as well as the aerial imagery $\left(R^{2} \geq 0.85\right.$, RMSE $\leq 3.9 \mathrm{~g} \mathrm{~kg}^{-1}$ ) (Fig. 8; Table 3). When applied to the sensor validation data, the prediction accuracy of OM decreases for both sensor ${ }_{\mathrm{AMBER}}$ and sensor ${ }_{\mathrm{NIR}}$ compared to a field-specific strategy. When the intercept-adjusted strategy is applied to the imagery validation data, all three bands give more accurate predictions of OM compared to the validation data using the field-specific strategy. This is attributed to the original moderately large correlation coefficients between the imagery bands and measured OM ( $r=-0.5$ to -0.7 ), and the smoothing effect that occurs when one predictive model is applied to several fields rather than individual fields. Performance of the model is enhanced due to the larger range of values when using all the fields together to define the slope of sensor response to the change in OM. Soil texture may be a significant factor affecting this slope, as was observed in the relationship between sensor readings and measured OM.

Based on sensor and imagery performance in the intercept-adjusted strategy, we tested the use of a combination of sensor and imagery data for predicting OM. Use of both sensor $_{\mathrm{AMBER}}$ and sensor $_{\mathrm{NIR}}$ (Fig. 9) gives results that are comparable to the use of sensor $_{\text {AMBER }}$ only $\left(R^{2}=0.78, \quad \mathrm{RMSE}=4.5 \mathrm{~g} \mathrm{~kg}^{-1}, \quad \mathrm{MAE}=3.4 \mathrm{~g} \mathrm{~kg}^{-1} ; \quad\right.$ Fig. 8 and Table 3). Because image $_{\text {GREEN }}$ and image $_{\text {RED }}$ were shown to be more accurate than image $_{\text {NIR }}$, the average of image ${ }_{\text {GREEN }}$ and image $\mathrm{RED}_{\mathrm{R}}$ was combined with sensor $\mathrm{AMBER}_{\mathrm{A}}$, resulting in $R^{2}=0.82$, RMSE $=4.1 \mathrm{~g} \mathrm{~kg}^{-1}$ and $\mathrm{MAE}=3.1 \mathrm{~g} \mathrm{~kg}^{-1}$. A combination of

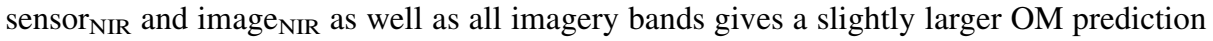
error. A combination of sensor ${ }_{\mathrm{AMBER}}$ and image $\mathrm{GREEN}_{\mathrm{G}}$ results in a model prediction accuracy comparable to that determined for the field-specific strategy $\left(R^{2}=0.82\right.$, RMSE $=4.1 \mathrm{~g} \mathrm{~kg}^{-1}, \mathrm{MAE}=3.1 \mathrm{~g} \mathrm{~kg}^{-1}$ ). These results indicate that a combination of sensor and imagery data does not significantly increase OM prediction accuracy.

A summary of the RMSE and MAE calculated for each strategy is given in Table 4. For each field in the table, bold values indicate the OM prediction strategies that produce the smallest MAEs, and the superscripts indicate strategies with significantly larger MAEs. These results indicate that the most accurate predictions of OM are obtained for Field 2 using the field-specific or intercept-adjusted strategy, with interpolation in Field 4 and with any method other than uniform or universal for Fields 1, 3, 5 and 6. The uniform and universal strategies provide the least accurate predictions of $\mathrm{OM}$ across all fields in this study compared with the other methods tested. Overall, a field-specific strategy using sensor $_{\text {AMBER }}$ results in the smallest MAE, but this was not significantly better than interpolation or other strategies that incorporated imagery bands. It should also be noted that the validation dataset results in a MAE of $\sim 3.3 \mathrm{~g} \mathrm{~kg}^{-1}$ for any of the field-specific or intercept-adjusted strategies. The interpolation methods result in a non-significant increase of MAE to $3.5 \mathrm{~g} \mathrm{~kg}^{-1}$, whereas the MAE for a uniform approach is significantly larger at $4.0 \mathrm{~g} \mathrm{~kg}^{-1}$. Finally, it is not feasible to use a single (universal) calibration model for the entire dataset. This is related to the range of soil texture, differences in soil moisture content at the time of data collection and the lack of a standardized range for sensor output values (sensor data only). A system that accounts for a wider range of soil texture and moisture contents could potentially produce a universal model to apply across a broad geographical area. Alternatively, increased prediction accuracy of OM could possibly be 

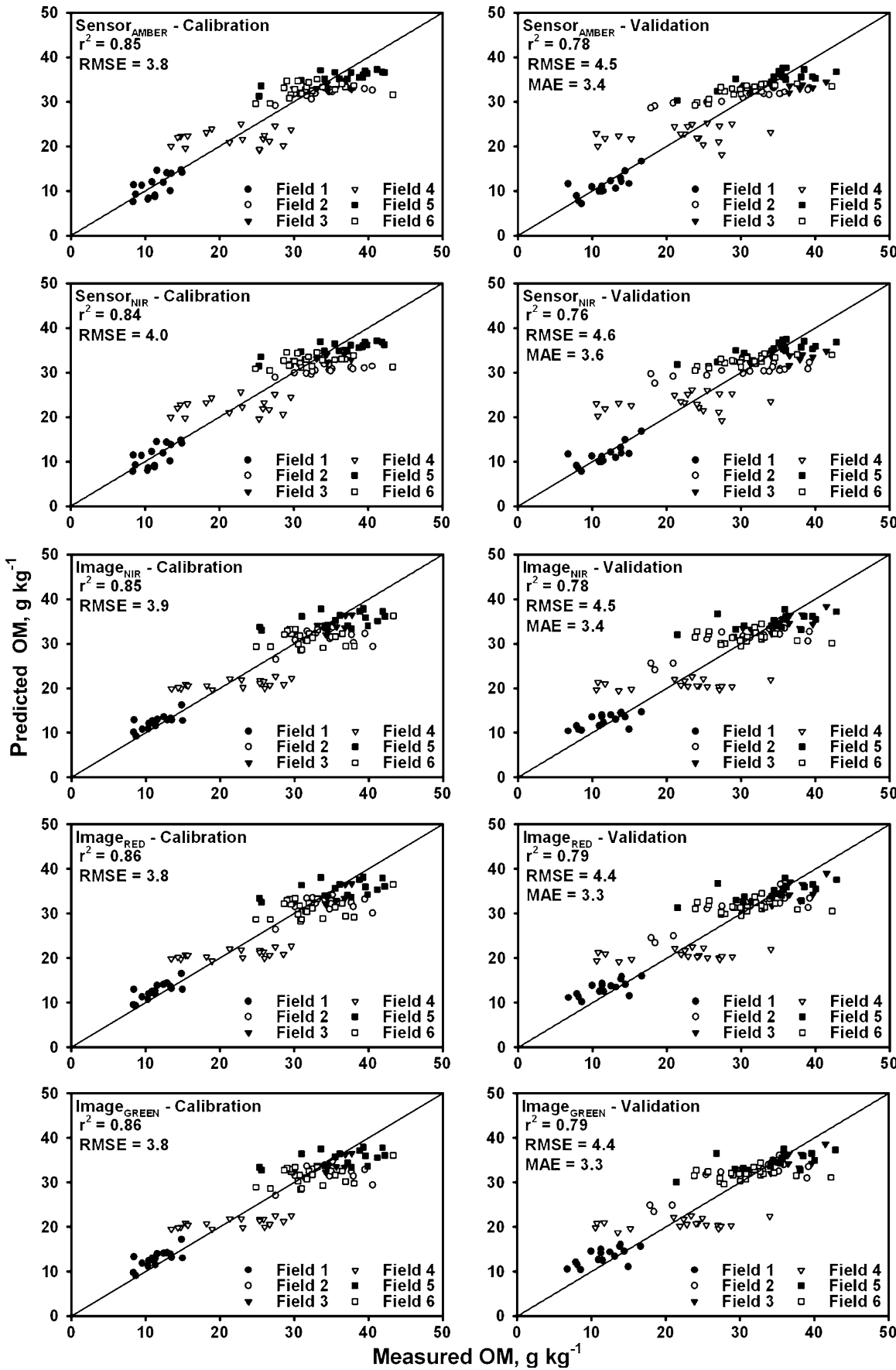

Fig. 8 Calibration and validation results of predicted versus measured OM for Fields 1-6 using the intercept-adjusted OM prediction strategy. A single regression model was applied across all fields. Intercept values were adjusted for each field based on three data points selected from high, medium and low OM areas of each field. The RMSE and MAE are in the same units as measured and predicted OM 

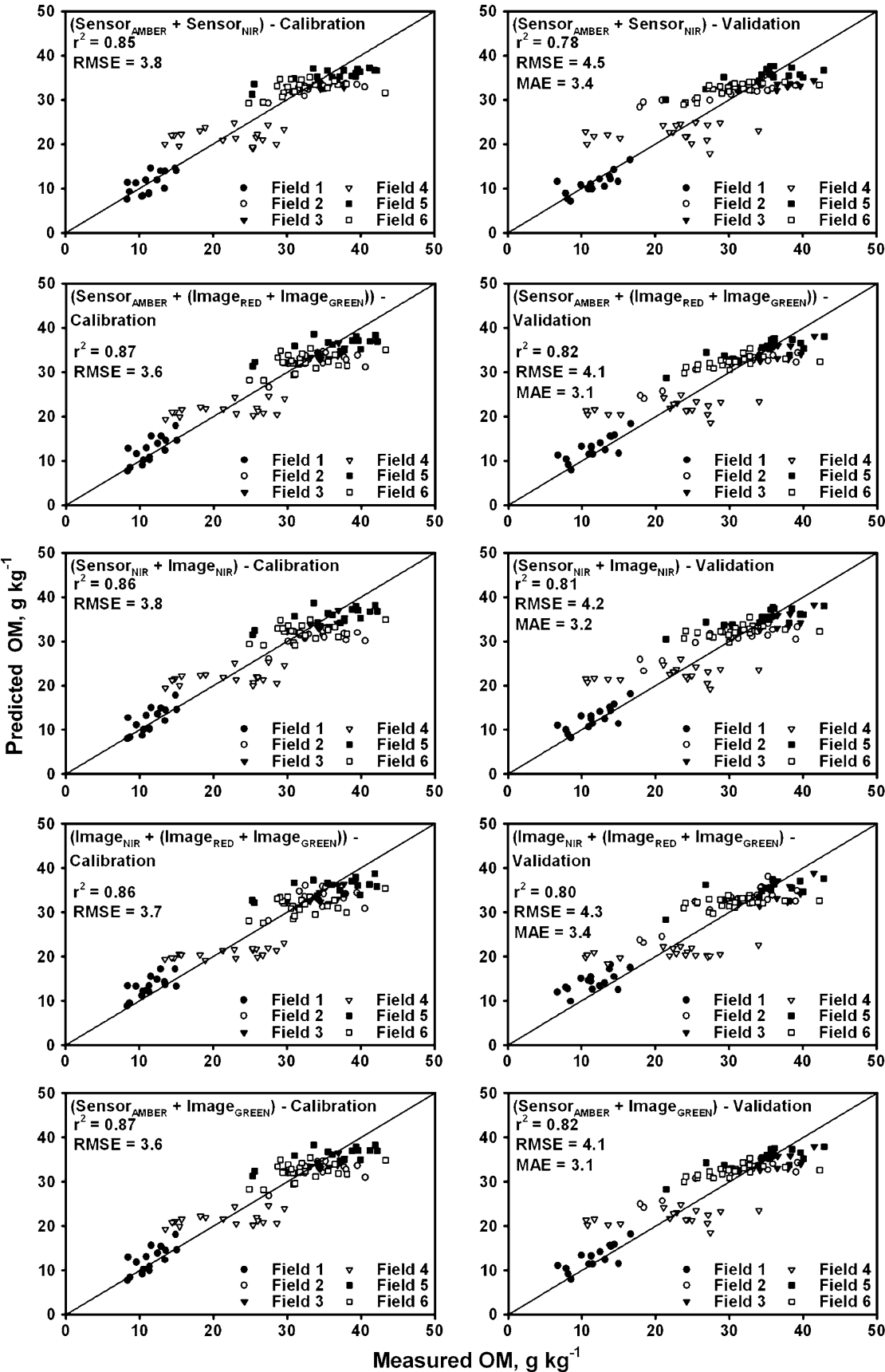

Fig. 9 Calibration and validation results of predicted OM versus measured OM for Fields 1-6 using a combination of multiple prediction variables and the intercept-adjusted OM prediction strategy. Prediction variables included sensor ${ }_{A M B E R}$ plus sensor ${ }_{N I R}$, sensor ${ }_{A M B E R}$ plus the average of image RED $_{\text {and }}$ image $_{\text {GREEN }}$, sensor NIR plus image $_{\text {NIR }}$, image NIR $_{\text {plus the average of image }}$ RED and image GREEN $_{\text {, and }}$

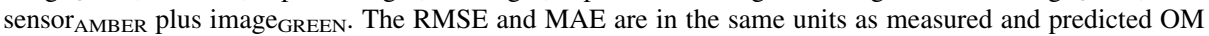




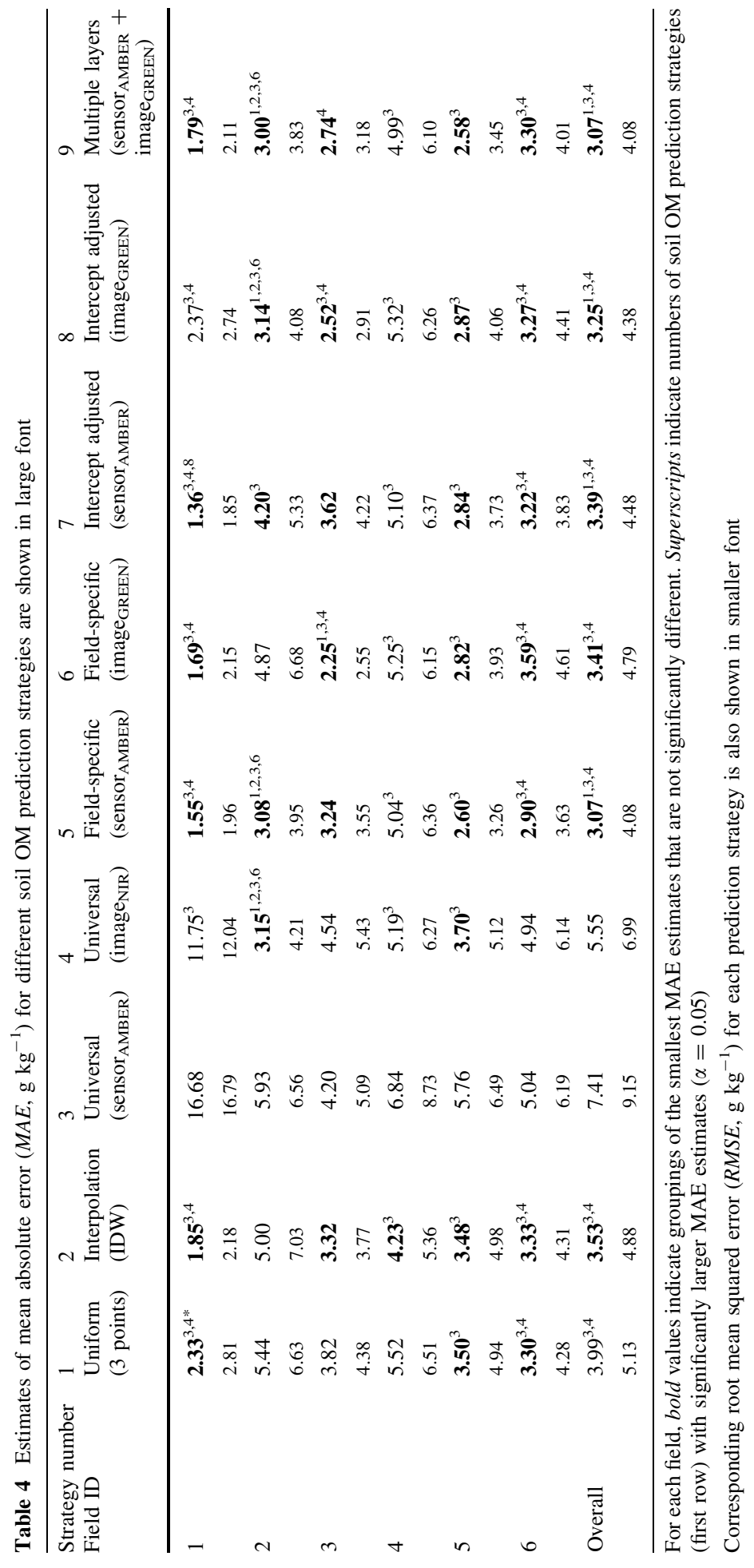


achieved by dividing the $0-20 \mathrm{~cm}$ soil samples into surface $(0-1 \mathrm{~cm})$ and subsurface $(1-$ $20 \mathrm{~cm}$ ) increments.

Although there was no significant difference in accuracy between sensor- and imagerybased OM estimates, these results show that specific field environments influenced sensorbased measurements more than imagery-based measurements. This could be attributed to the scaling of digital pixel values during the processing of aerial images, whereas a similar standardization is not performed on sensor data. Also, this difference could possibly be related to the bandwidths and wavelengths recorded for each sensing system. Although it would have been preferable to record data from the same wavelengths with both sensing systems, this study provides an initial analysis of two sensing systems available to producers. A follow-up study could include a comparison between the two platforms when similar data filters are used in both systems.

\section{Conclusions}

In this study, we have shown that surface soil OM can be predicted from a wide-band aerial image or a ground-based active sensor. We found that it was not feasible to use a single (universal) calibration model for the entire dataset. However, by adjusting regression intercept values for each field, OM was predicted using a single sensor or image waveband with an $R^{2} \geq 0.76$, RMSE $\leq 4.6 \mathrm{~g} \mathrm{~kg}^{-1}$ and MAE $\leq 3.6 \mathrm{~g} \mathrm{~kg}^{-1}$. This degree of accuracy of prediction is likely to be acceptable for use in the site-specific control of input rates for nitrogen fertilizer or pesticides, for example. Soil OM prediction using a ground-based sensor or an aerial image may be field-specific and not always significantly better compared to a conventional practice such as the assumption of uniform OM or interpolated estimates from sample data on a grid. Increased accuracy in soil OM prediction using an active sensor or aerial imagery may be obtained by acquiring the data when there is minimal surface residue or when it has been removed from the sensor field-of-view, by accounting for soil moisture content through the use of supplementary sensors at the time of data collection or by focusing on the relationship between soil reflectance and soil OM content in the $0-1 \mathrm{~cm}$ soil depth.

Acknowledgments This publication is a contribution of the University of Nebraska Agricultural Research Division, supported in part by funds provided through the Hatch Act. The authors express their appreciation to Glen Slater, Ryan Gerloff, Dennis Francis, Luciano Shiratsuchi, Aaron Bereuter, Jeff Shanle, Luke Pesek, Paul Koerner, and Susan Wagner for their assistance with data collection, sample processing, and soil laboratory analysis. The authors gratefully acknowledge local producers Evan Brandes, Brandon Hunnicutt, and Fred Schroeder for use of their farms in conducting this study.

\section{References}

Alexander, J. D. (1969). A color chart for organic matter. Crops and Soils, 21, 15-17.

Blackmer, A. M., \& White, S. E. (1998). Using precision farming technologies to improve management of soil and fertiliser nitrogen. Australian Journal of Agricultural Research, 49, 555-564.

Chen, F., Kissel, D. E., West, L. T., \& Adkins, W. (2000). Field-scale mapping of surface soil organic carbon using remotely sensed imagery. Soil Science Society of America Journal, 64, 746-753.

Chen, F., Kissel, D. E., West, L. T., Rickman, D., Luvall, J. C., \& Adkins, W. (2005). Mapping surface soil organic carbon for crop fields with remote sensing. Journal of Soil and Water Conservation, 60, 51-57.

Dellinger, A. E., Schmidt, J. P., \& Beegle, D. B. (2008). Developing nitrogen fertilizer recommendations for corn using an active sensor. Agronomy Journal, 100, 1546-1552. 
Diaz, R. J. (2001). Overview of hypoxia around the world. Journal of Environmental Quality, 30, $275-281$.

Gomez, C., Rossel, R. A. V., \& McBratney, A. B. (2008). Soil organic carbon prediction by hyperspectral remote sensing and field vis-NIR spectroscopy: An Australian case study. Geoderma, 146, 403-411.

Griffis, C. L. (1985). Electronic sensing of soil organic matter. Transactions of the ASAE, 28, 703-705.

Idso, S. B., Jackson, R. D., Reginato, R. J., Kimball, B. A., \& Nakayama, F. S. (1975). The dependence of bare soil albedo on soil water content. Journal of Applied Meteorology, 14, 109-113.

Knowler, D., \& Bradshaw, B. (2007). Farmers' adoption of conservation agriculture: A review and synthesis of recent research. Food Policy, 32, 25-48.

Krishnan, P., Alexander, J. D., Butler, B. J., \& Hummel, J. W. (1980). Reflectance technique for predicting soil organic matter. Soil Science Society of America Journal, 44, 1282-1285.

Nelson, D. W., \& Sommers, L. E. (1996). Total carbon, organic carbon, and organic matter. In D. L. Sparks (Ed.), SSSA book series no. 5, methods of soil analysis, Part 3-chemical methods (pp. 1002-1005). Madison, WI: Soil Science Society of America.

Pitts, M. J., Hummel, J. W., \& Butler, B. J. (1986). Sensors utilizing light reflection to measure soil organic matter. Transactions of the ASAE, 29, 422-428.

Post, D. F., Fimbres, A., Matthias, A. D., Sano, E. E., Accioly, L., Batchily, A. K., et al. (2000). Predicting soil albedo from soil color and spectral reflectance data. Soil Science Society of America Journal, 64, 1027-1034.

Raun, W. R., Solie, J. B., Johnson, G. V., Stone, M. L., Mullen, R. W., Freeman, K. W., et al. (2002). Improving nitrogen use efficiency in cereal grain production with optical sensing and variable rate application. Agronomy Journal, 94, 815-820.

Raun, W. R., Solie, J. B., Stone, M. L., Martin, K. L., Freeman, K. W., Mullen, R. W., et al. (2005). Optical sensor-based algorithm for crop nitrogen fertilization. Communications in Soil Science and Plant Analysis, 36, 2759-2781.

Roberts, D. F., Adamchuk, V. I., Shanahan, J. F., Ferguson, R. B., \& Schepers, J. S. (2009). Optimization of crop canopy sensor placement for measuring nitrogen status in corn. Agronomy Journal, 101, 140-149.

Scharf, P. C., Schmidt, J. P., Kitchen, N. R., Sudduth, K. A., Hong, S. Y., Lory, J. A., et al. (2002). Remote sensing for nitrogen management. Journal of Soil and Water Conservation, 57, 518-524.

Schepers, A. R., Shanahan, J. F., Liebig, M. A., Schepers, J. S., Johnson, S. H., \& Luchiari, A., Jr. (2004). Appropriateness of management zones for characterizing spatial variability of soil properties and irrigated corn yields across years. Agronomy Journal, 96, 195-203.

Schmidt, J. P., Dellinger, A. E., \& Beegle, D. B. (2009). Nitrogen recommendations for corn: An on-the-go sensor compared with current recommendation methods. Agronomy Journal, 101, 916-924.

Schulze, D. G., Nagel, J. L., Van Scoyoc, G. E., Henderson, T. L., Baumgardner, M. F., \& Stott, D. E. (1993). Significance of organic matter in determining soil colors. In J. M. Bigham \& E. J. Ciolkosz (Eds.), Soil color (pp. 71-90). Soil science society of America special publication number 31. Madison, WI: Soil Science Society of America.

Shanahan, J. F., Kitchen, N. R., Raun, W. R., \& Schepers, J. S. (2008). Responsive in-season nitrogen management for cereals. Computers and Electronics in Agriculture, 61, 51-62.

Shapiro, C. A., Ferguson, R. B., Hergert, G. W. Dobermann, A. R., \& Wortmann C. S. (2003). Fertilizer suggestions for corn. NebGuide G174, University of Nebraska.

Solari, F., Shanahan, J. F., Ferguson, R. B., Schepers, J. S., \& Gitelson, A. A. (2008). Active sensor reflectance measurements of corn nitrogen status and yield potential. Agronomy Journal, 100, 571579.

Steinhardt, G. C., \& Franzmeier, D. P. (1979). Comparison of organic matter content with soil color for silt loam soils of Indiana. Communications in Soil Science and Plant Analysis, 10, 1271-1277.

Sudduth, K. A., \& Hummel, J. W. (1991). Evaluation of reflectance methods for soil organic matter sensing. Transactions of the ASAE, 34, 1900-1909.

Sudduth, K. A., \& Hummel, J. W. (1993). Soil organic matter, CEC, and moisture sensing with a portable NIR spectrophotometer. Transactions of the ASAE, 36, 1571-1582.

Weber, J. B., Taylor, K. A., \& Wilkerson, G. G. (2006). Soil and herbicide properties influenced mobility of atrazine, metolachlor, and primisulfuron-methyl in field lysimeters. Agronomy Journal, 98, 8-18. 